Research Paper

\title{
Efficacy of Lamivudine or Entecavir against Virological Rebound after Achieving HBV DNA Negativity in Chronic Hepatitis B Patients
}

Tomoo Miyauchi ${ }^{1, *}$, Tatsuo Kanda ${ }^{1,}{ }^{*}, \bowtie$, Masami Shinozaki ${ }^{2}$, Hidehiro Kamezaki ${ }^{1}$, Shuang $\mathrm{Wu}^{1}$, Shingo Nakamoto ${ }^{1}$, Kazuki Kato ${ }^{3}$, Makoto Arai ${ }^{1}$, Shigeru Mikamii ${ }^{4}$, Nobuyuki Sugiura ${ }^{5}$, Michio Kimura ${ }^{3}$, Nobuaki Goto $^{2}$, Fumio Imazeki ${ }^{1,6}$, and Osamu Yokosuka ${ }^{1}$

1. Department of Gastroenterology and Nephrology, Chiba University, Graduate School of Medicine, Chiba (260-8677), Japan.

2. Department of Gastroenterology, Numazu City Hospital, Numazu (410-0302), Japan.

3. Department of Medicine, Social Insurance Funabashi Central Hospital, Funabashi (273-8556), Japan.

4. Department of Gastroenterology, Kikkoman General Hospital, Noda (278-0005), Japan.

5. Department of Gastroenterology, National Hospital Organization Chiba Medical Center, Chiba (260-8606), Japan.

6. Safety and Health Organization, Chiba University, Chiba (263-8522), Japan.

*These authors contributed equally.

$\triangle$ Corresponding author: Tatsuo Kanda, M.D., Associate Professor, Department of Gastroenterology and Nephrology, Chiba University, Graduate School of Medicine, 1-8-1 Inohana, Chuo-ku, Chiba (260-8677), Japan. Tel: +81-43-226-2086, Fax: +81-43-226-2088; Email: kandat-cib@umin.ac.jp.

(c) Ivyspring International Publisher. This is an open-access article distributed under the terms of the Creative Commons License (http://creativecommons.org/ licenses/by-nc-nd/3.0/). Reproduction is permitted for personal, noncommercial use, provided that the article is in whole, unmodified, and properly cited.

Received: 2013.0I.I8; Accepted: 2013.03.27; Published: 2013.04.0I

\begin{abstract}
Nucleos(t)ide analogues (NAs) lead to viral suppression and undetectable hepatitis $B$ virus (HBV) DNA in some individuals infected with HBV, but the rate of virological rebound has been unknown in such patients. We examined the prevalence of virological rebound of HBV DNA among NA-treated patients with undetectable HBV DNA. We retrospectively analyzed 303 consecutive patients [158 entecavir (ETV)- and I45 lamivudine (LAM)-treated] who achieved HBV DNA negativity, defined as HBV DNA $<3.7 \log \mathrm{IU} / \mathrm{mL}$ for at least 3 months. They were followed up and their features, including their rates of viral breakthrough, were determined. Viral rebound after HBV DNA negativity was not observed in the ETV-group. Viral rebound after HBV DNA negativity occurred in $38.7 \%$ of $62 \mathrm{HBe}$ antigen-positive patients in the LAM-group. On multivariate analysis, age was an independent factor for viral breakthrough among these patients $(P=0.035)$. Viral rebound after HBV DNA negativity occurred in $29.1 \%$ of $79 \mathrm{HBe}$ antigen-negative patients in the LAM-group. Differently from LAM, ETV could inhibit HBV replication once HBV DNA negativity was achieved. In contrast, LAM could not inhibit HBV replication even if HBV negativity was achieved in the early phase. Attention should be paid to these features in clinical practice.
\end{abstract}

Key words: Entecavir, HBeAg, HBV DNA, Lamivudine, Virological rebound.

\section{INTRODUCTION}

Hepatitis B virus (HBV) infection remains a major health problem and one of the risk factors for the development of hepatocellular carcinoma (HCC) worldwide [1,2]. Chronic HBV infection has been linked epidemiologically to the development of HCC for more than 30 years [3]. To date, the mechanism of HBV-related hepatocarcinogenesis is not clear. Although effective vaccine exists for preventing HBV 
infection [4], acute liver failure due to HBV or acute exacerbation of chronic hepatitis $\mathrm{B}$ is also a life-threatening disease $[5,6]$.

Positivity for hepatitis B e antigen (HBeAg), which in serum indicates active viral replication in hepatocytes, is associated with an increased risk of HCC [7]. Chronic HBV carriers with high-titer viremia are also at increased risk for HCC [8]. The risk for cirrhosis and that for HCC increase significantly with increasing HBV DNA levels $[9,10]$. Thus, it cannot be overstated that HBV DNA should be directly suppressed to prevent the development of HCC.

There are several nucleos(t)ide analogues (NAs) for the treatment of chronic hepatitis B [11]. Currently, the Japanese national health insurance system approves lamivudine (LAM) and entecavir (ETV) as first-line therapy for treatment-naïve patients with chronic hepatitis $\mathrm{B}$, although some patients are treated with standard interferon-alfa or peginterferon-alfa-2a $[6,12]$. In general, LAM, the first oral NA available for the treatment of chronic hepatitis B, is associated with high rates of drug-resistance, with $\sim 76 \%$ after 8 years of treatment $[13,14]$. ETV is found to be superior to LAM from the point of view that ETV is stronger than LAM and that resistance to ETV is rare, about $1.2 \%$ after 5 years of ETV treatment $[14,15]$.

The aim of this study was to determine the efficacy and the rates of virological rebound after achieving HBV DNA negativity in the use of ETV or LAM in clinical practice. Our study showed that ETV could inhibit HBV replication if HBV DNA negativity had been achieved, but LAM was unable to inhibit $\mathrm{HBV}$ replication even if HBV negativity was achieved in the early phase.

\section{MATERIALS AND METHODS}

\section{Patients and Study Design}

This was a retrospective analysis comparing the rates of virological rebound in patients treated with ETV versus those in patients treated with LAM. A total of 303 patients were examined from Chiba University Hospital, Chiba, Japan, and 4 affiliated hospitals between the period of January 2000 and December 2011. NAs-naïve chronic hepatitis B patients daily receiving $0.5 \mathrm{mg}$ of ETV (ETV group, $\mathrm{N}=158$ ) or receiving $100 \mathrm{mg}$ of LAM (LAM group, $\mathrm{N}=145$ ) with undetectable HBV DNA $(<3.7 \log \mathrm{IU} / \mathrm{mL})$ for three months were enrolled. Some of the included patients had been previously reported [12, 16]. All patients had serum hepatitis B surface antigen (HBsAg) detectable for at least 6 months, regardless of their HBeAg status. They were negative for hepatitis C virus and human immunodeficiency virus antibodies.
This study was approved by the Ethics Committee of Chiba University, Graduate School of Medicine (No. 977).

\section{Definition of Virological Rebound of HBV}

We defined virological rebound as $\geq 3.7 \mathrm{log}$ $\mathrm{IU} / \mathrm{mL}$ for at least 3 months after achieving undetectable HBV DNA.

\section{Monitoring of HBV DNA, Serum Liver Func- tion Tests and Hematological Tests}

The primary outcome of this study was the virological rebound. Patients were followed up at least every 3 months to examine physical status and to monitor liver biochemistry and virology. All clinical laboratory tests including hematological data, biochemical data, and HBV serologies were performed at the Central Laboratory of Chiba University Hospital. $\mathrm{HBsAg}, \mathrm{HBeAg}$ and anti-HBe antibody were determined by ELISA (Abbott, Chicago, IL, USA) or CLEIA (Fujirebio, Tokyo, Japan) [17]. HBV genotype was determined from patients' sera by ELISA (Institute of Immunology, Tokyo, Japan) as reported by Usuda et al [18]. HBV DNA was measured by transcription-mediated amplification (TMA) assay, COBAS Amplicor HBV Monitor assay, or COBAS TaqMan (Roche Diagnostics, Branchburg, NJ, USA). The clinical efficacy of NAs was assessed as the proportion of patients achieving HBV DNA negativity, defined as an HBV DNA level of $<3.7 \log \mathrm{IU} / \mathrm{mL}$.

\section{Statistical analysis}

Data were expressed as mean \pm standard deviation (SD). Differences were evaluated by Student's $t$-test, chi-square test, or Fisher's exact test. $P<0.05$ was considered statistically significant. Variables with $P<0.05$ at univariate analysis were retained for multivariate logistic-regression analysis. For all tests, two-sided P-values were calculated and the results were considered statistically significant at $P<0.05$. Statistical analysis was performed using the Excelstatistics program for Windows, version 7 (SSRI, Tokyo, Japan).

\section{RESULTS}

A total 303 patients were recruited into either the ETV group $(n=158)$ or the LAM group $(n=145)$, with a follow-up period of $33.7 \pm 11.3$ months $(28.6 \pm 11.3$ months or $39.3 \pm 31.4$ months, respectively). Baseline demographic and laboratory data are summarized in Table 1. There were no differences in age, gender, HBV DNA, alanine aminotransferase (ALT) levels, ultrasound findings/presence of cirrhosis, and periods from the initial administration of ETV or LAM to 
undetectable HBV DNA, between the ETV and LAM groups, although the proportion of HBeAg-positive patients in the ETV group (55\%) tended to be higher than that in the LAM group (44\%).

\section{Virological Rebound}

The patient flow and outcome are summarized in Figure 1. We excluded 9 patients, whose HBeAg status at baseline was unknown, from this analysis. When comparing the baseline characteristics of patients according to $\mathrm{HBeAg}$ status, HBeAg-positive patients were younger, had higher ALT levels and HBV DNA levels, and less cirrhotic findings by ultrasound than HBeAg-negative patients (Table 2). The period from the initial administration of ETV or LAM to the determination of undetectable HBV DNA in the HBeAg-negative group tended to be shorter than that in the HBeAg-positive group (Table 2).

In the ETV group, none of the patients had virological rebound during the follow-up periods. In the LAM group, 24 and 23 patients of 62 $\mathrm{HBeAg}$-positive and $79 \mathrm{HBeAg}$-negative patients at baseline, respectively, developed evidence of virological rebound. In the $24 \mathrm{HBeAg}$-positive patients at baseline with virological rebound, 9, 8, 3, 1, 2, and 1 had virological rebound at $\leq 1,1 \sim \leq 2,2 \sim \leq 3,3 \sim 4$, $4 \sim \leq 5$, and details unknown, respectively. In the 23 $\mathrm{HBeAg}$-negative patients at baseline with virological rebound, 10, 8, 3, 0, 1, and 1 had virological rebound at $\leq 1,1 \sim \leq 2,2 \sim \leq 3,3 \sim \leq 4,4 \sim \leq 5$ and details unknown, respectively. Baseline characteristics of patients treated with ETV or LAM according to HBeAg status are shown in Table 3. In the ETV group, the period from the initial administration of ETV to the determination of undetectable HBV DNA in the HBeAg-negative group was the same as that in the HBeAg-positive group (Table 3). In the LAM group, the period from the initial administration of LAM to undetectable HBV DNA in the HBeAg-negative group was shorter than that in the HBeAg-positive group (Table 3 ). In the HBeAg-positive patients, the period from the initial administration to undetectable HBV DNA in the ETV group was shorter than that in the LAM group (Table 3).

\section{Predictors of Virological Rebound in Patients treated with LAM}

To clarify the predictors of virological rebound in patients treated with LAM, we compared the pretreatment factors between patients with and without virological rebound according to HBeAg status (Table 4A \& 4B). Univariative analysis showed that age, HBV DNA, ALT levels and the period from the initial administration of LAM to the determination of undetectable HBV DNA in HBeAg-positive patients contributed to the occurrence of virological rebound (Table 4A). Factors significantly associated with virological rebound in $\mathrm{HBeAg}$-positive patients treated with LAM by univariate analysis were also analyzed by multivariate logistic regression analysis. Virological rebound was attained independently of age in HBeAg-positive patients treated with LAM (Table 4C). In HBeAg-negative patients, no significant factors contributing to virological rebound could be found (Table 4B).

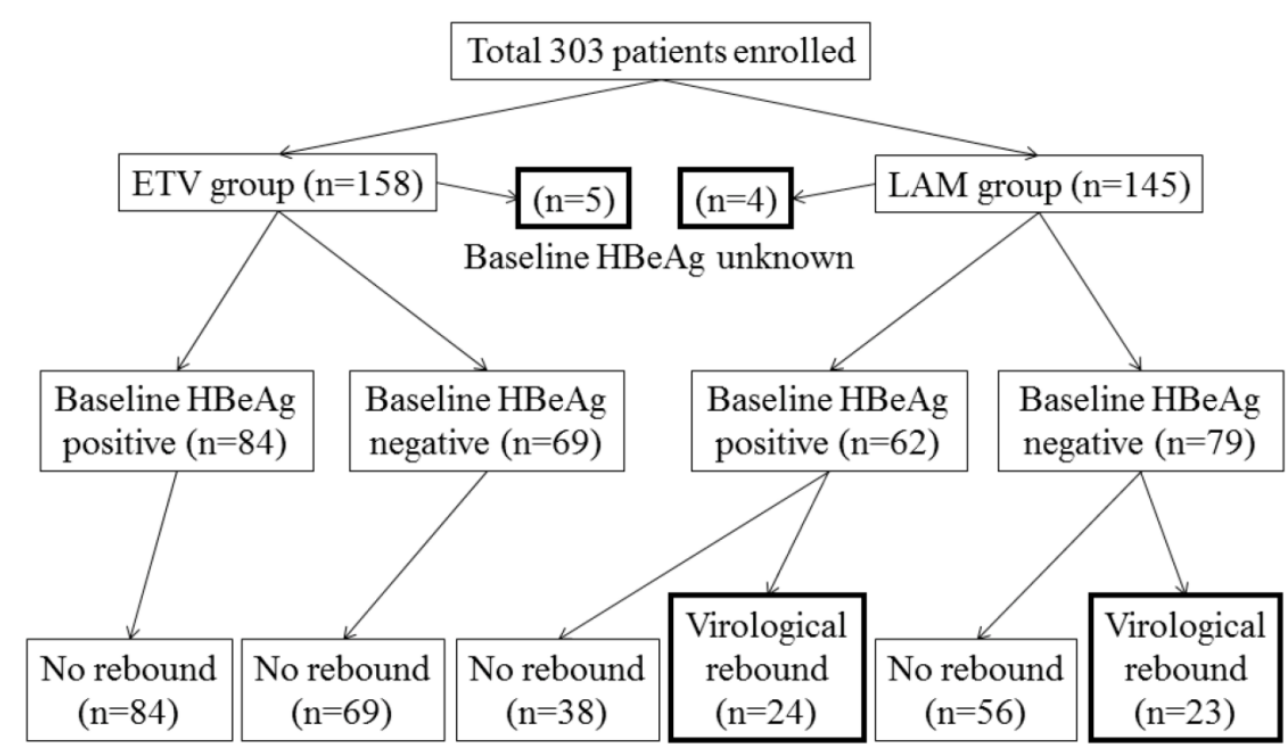

Figure I. Study design and patient flow for both groups. 
Table I. Baseline characteristics of patients treated with entecavir (ETV) or lamivudine (LAM).

\begin{tabular}{|c|c|c|c|c|}
\hline & Total & ETV group & LAM group & $P$-values \\
\hline Number & 303 & 158 & 145 & \\
\hline Age (years) & $51 \pm 12$ & $51 \pm 12$ & $50 \pm 12$ & N.S. \\
\hline Gender (male) & 205 & 101 & 104 & N.S. \\
\hline $\operatorname{HBeAg}(+)$ & 146 & 84 & 62 & 0.079 \\
\hline HBV DNA $(\log I U / m L)$ & $6.5 \pm 1.5$ & $6.6 \pm 1.7$ & $6.4 \pm 1.3$ & N.S. \\
\hline $\operatorname{ALT}(\mathrm{IU} / \mathrm{L})$ & $203 \pm 280$ & $187 \pm 290$ & $220 \pm 266$ & N.S. \\
\hline US: Cirrhosis $(+)$ & 113 & 56 & 57 & N.S. \\
\hline Periods to undetectable HBV DNA (months) & $10.0 \pm 18.2$ & $8.5 \pm 11.9$ & $11.8 \pm 23.3$ & N.S. \\
\hline
\end{tabular}

Data are expressed as mean + SD. ETV group, patients receiving $0.5 \mathrm{mg}$ of ETV daily; LAM group, patients receiving $100 \mathrm{mg}$ of LAM daily; $P$-values, $P$-values between ETV and LAM groups; HBeAg, hepatitis B e antigen; ALT, alanine aminotransferase; US, ultrasound findings; N.S., no statistically significant difference.

Table 2. Baseline characteristics of patients according to $\mathrm{HBeAg}$ status.

\begin{tabular}{llll}
\hline HBeAg & Positive group & Negative group & $P$-values \\
\hline Number & 146 & 148 & $<0.001$ \\
Age (years) & $46 \pm 12$ & $55 \pm 11$ & N.S. \\
Gender (male) & 101 & 97 & $<0.001$ \\
HBV DNA (log IU/mL) & $7.2 \pm 1.1$ & $5.8 \pm 1.4$ & 0.002 \\
ALT (IU/L) & $257 \pm 332$ & $156 \pm 211$ & $<0.001$ \\
US: Cirrhosis (+) & 41 & 70 & 0.063 \\
Periods to undetectable HBV DNA (months) & $11.0 \pm 18.1$ & $7.4 \pm 14.4$ &
\end{tabular}

Data are expressed as mean \pm SD. $P$-values, $P$-values between HBeAg-positive and HBeAg-negative groups; HBeAg, hepatitis B e antigen; ALT, alanine aminotransferase; US, ultrasound findings; N.S., no statistically significant difference.

Table 3. Baseline characteristics of patients treated with entecavir (ETV) or lamivudine (LAM) according to $\mathrm{HBeAg}$ status.

\begin{tabular}{lllll}
\hline & ETV group & \multicolumn{3}{c}{ LAM group } \\
\hline HBeAg & Positive & Negative & Positive & Negative \\
Number & 84 & 69 & 62 & 79 \\
Age (years) & $48 \pm 12$ & $56 \pm 11^{*}$ & $44 \pm 11^{\# \#}$ & $54 \pm 11^{* *}$ \\
Gender (male) & 53 & 45 & 48 & $52^{* *}$ \\
HBV DNA (log IU/mL) & $7.5 \pm 1.1$ & $5.7 \pm 1.5^{*}$ & $6.9 \pm 1.1^{\$}$ & $5.9 \pm 1.3^{* *}$ \\
ALT (IU/L) & $219 \pm 325$ & $159 \pm 246$ & $309 \pm 334$ & $154 \pm 174^{* *}$ \\
US: Cirrhosis (+) & 25 & 29 & 16 & 41 \\
Periods to undetectable HBV DNA (months) & $8.3 \pm 10.5$ & $7.3 \pm 11.0$ & $15.0 \pm 24.7^{\$ \$}$ & $7.5 \pm 16.9^{\#}$
\end{tabular}

Data are expressed as mean \pm SD. HBeAg, hepatitis B e antigen; ALT, alanine aminotransferase; US, ultrasound findings; ${ }^{*} P<0.001$, compared to HBeAg-positive of ETV group; ${ }^{*} P<0.001$ and $\# P=0.034$, compared to HBeAg-positive of LAM group; $\# \# P=0.041, \$ P=0.001$ and $\$ \$ P=0.027$, compared to HBeAg-positive of ETV group.

Table 4A. Predictors of virological rebound in patients treated with lamivudine (LAM). (A) Comparison of HBeAg-positive patients with or without virological rebound by univariate analysis.

\begin{tabular}{llll}
\hline Virological rebound & No & Yes & P-values \\
\hline Number & 38 & 23 & \\
Age (years) & $42 \pm 11$ & $49 \pm 11$ & 0.019 \\
Gender (male) & 30 & 17 & N.S. \\
HBV DNA (log IU/mL) & $6.9 \pm 1.2$ & $6.8 \pm 0.9$ & N.S. \\
ALT (IU/L) & $379 \pm 377$ & $196 \pm 205$ & 0.037 \\
US: Cirrhosis (+) & 7 & 9 & N.S. \\
Periods to undetectable HBV DNA (months) & $20.6 \pm 29.1$ & $4.1 \pm 3.1$ & 0.009 \\
\hline
\end{tabular}

Data are expressed as mean \pm SD. $P$-values, $P$-values between patients with or without virological rebound groups; HBeAg, hepatitis B e antigen; ALT, alanine aminotransferase; US, ultrasound findings; N.S., no statistically significant difference. 
Table 4B. (B) Comparison of HBeAg-negative patients with or without virological rebound by univariate analysis.

\begin{tabular}{|c|c|c|c|}
\hline Virological rebound & No & Yes & P-values \\
\hline Number & 56 & 22 & \\
\hline Age (years) & $54 \pm 11$ & $54 \pm 10$ & N.S. \\
\hline Gender (male) & 40 & 12 & N.S. \\
\hline HBV DNA $(\log \mathrm{IU} / \mathrm{mL})$ & $5.9 \pm 1.4$ & $5.9 \pm 1.0$ & N.S. \\
\hline ALT (IU/L) & $163 \pm 179$ & $137 \pm 163$ & N.S. \\
\hline US: Cirrhosis $(+)$ & 30 & 11 & N.S. \\
\hline Periods to undetectable HBV DNA (months) & $7.3 \pm 14.8$ & $3.1 \pm 2.1$ & N.S. \\
\hline
\end{tabular}

Data are expressed as mean $\pm \mathrm{SD}$. $P$-values, $P$-values between patients with or without virological rebound groups; HBeAg, hepatitis B e antigen; ALT, alanine aminotransferase; US, ultrasound findings; N.S., no statistically significant difference.

Table 4C. (C) Factor associated with virological rebound among HBeAg-positive patients treated with LAM by multivariate analysis.

\begin{tabular}{lllll}
\hline Factor & Category & Odds ratio & $95 \%$ CI & $P$-value \\
\hline Age $\leq 44.5$ (years) & $(+/-)$ & 0.222 & $0.0547-0.9023$ & 0.0354 \\
\hline
\end{tabular}

\section{DISCUSSION}

To date, there is not much data regarding virological rebound after achieving HBV DNA negativity in the use of ETV or LAM. A recent report supported the merit of the change from LAM to ETV [14]. This study concluded that prior optimal viral suppression with ETV did not confer any significant advantage for patients who switched to LAM.

The present study revealed that ETV could suppress HBV replication after achieving HBV DNA negativity, although additional longer follow-up studies will be needed. On the other hand, LAM could not suppress HBV replication even after achieving HBV DNA negativity (Figure 1), although most cases with virological rebound were observed within 2 years of the start of LAM medication. We could not check the emergence of YMDD motif mutations [19] in all of the cases because the present study was performed as part of regular clinical practice. Of 2 of the $\mathrm{HBeAg}$-positive patients at baseline with virological rebound, one showed YVDD motif (50\%). In 4 of the HBeAg-negative patients at baseline with virological rebound, one YVDD motif (25\%) and three YIDD motifs $(75 \%)$ were seen. Virological rebound may not mean the emergence of NA-resistance mutations [12].

We do not know the reason why virological rebound was attained independently of age in HBeAg-positive patients treated with LAM. HBeAg to anti-HBe antibody seroconversions were found in 20 and 11 patients with and without virological rebound, that is, the HBeAg to anti-HBe antibody seroconversion rates were similar in the two groups (data not shown), although the number of study patients seemed small in the present study. Further studies might be needed. In any event, it might be important to consider the LAM-to-ETV switch in HBeAg-positive patients treated with LAM, although some of our patients in the LAM group remained HBV-negative throughout the observation period.

In the present study, $95.3 \%$ (122 of 128), 82.3\% (14 of 17 ) and $89.2 \%$ (25 of 28 ) had an adherence rate $>90 \%$ [16] in ETV-treated, LAM-treated with virological rebound and LAM-treated patients without virological rebound, respectively. These results supported our previous study that viral breakthrough associated with poor adherence could be a more important issue in the treatment with especially stronger NAs, such as ETV $[12,16]$, although we cannot ensure durable HBV negativity after NAs are discontinued. We and others reported that $\mathrm{HBeAg}$ could impair both innate and adaptive immune responses to promote chronic HBV infection $[16,20,21]$. Of interest, the virological rebound with the use of LAM seemed unrelated to the $\mathrm{HBeAg}$ status, suggesting that it was dependent on resistant mutation.

Recently, other effective antiviral therapies such as peginterferon [22,23] and tenofovir [24,25] were reported to be useful for the control of HBV infection. These drugs might also be candidates for treating virological rebound. Fung et al. [14] reported that prior optimal viral suppression with ETV did not confer any significant advantage for patients who switched to LAM. Our results also supported the previous studies that ETV was much more efficient than LAM [26-29]. In conclusion, ETV could inhibit HBV replication if HBV DNA negativity had been achieved. In contrast, LAM could not inhibit HBV replication even if HBV negativity was achieved in the early phase. Attention should be paid to these features in clinical 
practice.

\section{ACKNOWLEDGEMENTS}

We thank all our colleagues at the liver units of our hospitals who cared for the patients described herein.

\section{CONFLICT OF INTEREST}

Dr. Tatsuo Kanda reports receiving lecture fees from Chugai Pharmaceutical, MSD, and Ajinomoto, and Prof. Osamu Yokosuka received grant support from Chugai Pharmaceutical, Bayer, MSD, Daiichi-Sankyo, Mitsubishi Tanabe Pharma, and Bristol-Myers Squibb.

\section{ABBREVIATIONS}

ALT: alanine aminotransferase; ETV: Entecavir; HBeAg: Hepatitis B e antigen; HBsAg: Hepatitis B surface antigen; HBV: Hepatitis B virus; HCC: Hepatocellular carcinoma; LAM: lamivudine; NA: nucleos(t)ide analogue.

\section{REFERENCES}

1. Dandri M, Locarnini S. New insight in the pathobiology of hepatitis B virus infection. Gut. 2012; 61: i6-i17.

2. Di Bisceglie AM. Hepatitis B and hepatocellular carcinoma. Hepatology. 2009; 49 (5 Suppl): S56-S60.

3. Beasley RP, Hwang LY, Lin CC, et al. Hepatocellular carcinoma and hepatitis B virus. A prospective study of 22707 men in Taiwan. Lancet. 1981; 2: 1129-1133.

4. Lavanchy D. Viral hepatitis: global goals for vaccination. J Clin Virol. 2012; 55:296-302.

5. Imamura $\mathrm{T}$, Yokosuka O, Kurihara $\mathrm{T}$, et al. Distribution of hepatitis B virus genotypes and mutations in the core promoter and precore regions in acute form of liver disease in patients from Chiba, Japan. Gut. 2003; 52: 1630-1637.

6. Kanda T, Shinozaki M, Kamezaki H, et al. Efficacy of lamivudine or entecavir on acute exacerbation of chronic hepatitis B. Int J Med Sci. 2012; 9: 27-32.

7. Yang HI, Lu SN, Liaw YF, et al. Hepatitis B e antigen and the risk of hepatocellular carcinoma. N Engl J Med. 2002; 347: 168-174.

8. Harris RA, Chen G, Lin WY, et al. Spontaneous clearance of high-titer serum HBV DNA and risk of hepatocellular carcinoma in a Chinese population. Cancer Causes Control. 2003; 14: 995-1000.

9. Chen CJ, Yang HI, Su J, et al. Risk of hepatocellular carcinoma across a biological gradient of serum hepatitis B virus DNA level. JAMA. 2006; 295: 65-73.

10. Iloeje UH, Yang HI, Su J, et al. Predicting cirrhosis risk based on the level of circulating hepatitis B viral load. Gastroenterology. 2006; 130: 678-686.

11. Liaw $Y F$, Kao JH, Piratvisuth $T$, et al. Asian-Pacific consensus statement on the management of chronic hepatitis B: a 2012 update. Hepatol Int. 2012; 6: 531-561.

12. Kamezaki H, Kanda T, Wu S, et al. Emergence of entecavir-resistant mutations in nucleos $(\mathrm{t})$ ide-naïve Japanese patients infected with hepatitis B virus: virological breakthrough is also dependent on adherence to medication. Scand J Gastroenterol. 2011; 46: 1111-1117.

13. Yuen MF, Seto WK, Chow DH, et al. Long-term lamivudine therapy reduces the risk of long-term complications of chronic hepatitis B infection even in patients without advanced disease. Antivir Ther. 2007; 12: 1295-1303.

14. Fung J, Lai CL, Yuen J, et al. Randomized trial of lamivudine versus entecavir in Entecavir-treated patients with undetectable hepatitis B virus DNA: outcome at 2 years. Hepatology. 2011; 53: 1148-1153.

15. Tenney DJ, Rose RE, Baldick CJ, et al. Long-term monitoring shows hepatitis $B$ virus resistance to entecavir in nucleoside-naïve patients is rare through 5 years of therapy. Hepatology. 2009; 49: 1503-1514.
16. Kamezaki H, Kanda T, Makoto A, et al. Adherence to medication is a more important contributor to viral breakthrough in chronic hepatitis $\mathrm{B}$ patients treated with entecavir than in those with lamivudine. Int J Med Sci. 2013; 10: 567-574.

17. Wu S, Kanda T, Imazeki F, et al. Hepatitis B virus e antigen downregulates cytokine production in human hepatoma cell lines. Viral Immunol. 2010; 23: 467-476.

18. Usuda $\mathrm{S}$, Okamoto $\mathrm{H}$, Iwanari $\mathrm{H}$, et al. Serological detection of hepatitis $B$ virus genotypes by ELISA with monoclonal antibodies to type-specific epitopes in the preS2-region product. J Virol Methods. 1999; 80: 97-112.

19. Seta T, Yokosuka O, Imazeki F, et al. Emergence of YMDD motief mutations of hepatitis B virus during lamivudine treatment of immunocompetent type B hepatitis patients. J Med Virol. 2000; 60: 8-16.

20. Chen M, Sallberg M, Hughes J, et al. Immune tolerance split between hepatitis B virus precore and core proteins. J Virol. 2005; 79: 3016-3027.

21. Wu S, Kanda T, Imazeki F, et al. Hepatitis B virus e antigen physically associates with receptor-interacting serine/threonine protein kinase 2 and requires IL-6 gene expression. J Infect Dis. 2012; 206: 415-420.

22. Marcellin P, Lau GK, Bonino F, et al. Peginterferon alfa-2a alone, lamivudine alone, and the two in combination in patients with HBeAg-negative chronic hepatitis B. N Engl J Med. 2004; 351: 1206-1217.

23. Lau GK, Piratvisuth T, Luo KX, et al. Peginterferon Alfa-2a, lamivudine, and the combination for HBeAg-positive chronic hepatitis B. N Engl J Med. 2005; 352: 2682-2695.

24. Schildgen O, Sirma H, Funk A, et al. Variant of hepatitis B virus with primary resistance to adefovir. N Engl J Med. 2006; 354: 1807-1812.

25. Marcellin P, Heathcote EJ, Buti M, et al. Tenofovir disoproxil fumarate versus adefovir dipivoxil for chronic hepatitis B. N Engl J Med. 2008; 359: 2442-2455.

26. Chang TT, Gish RG, de Man R, et al. A comparison of Entecavir and lamivudine for HBeAg-positive chronic hepatitis B. N Engl J Med. 2006; 354: 1001-1010.

27. Lai CC, Shouval D, Lok AS, et al. Entecavir versus lamivudine for patients with HBeAg-negative chronic hepatitis B. N Engl J Med. 2006; 354: 1011-1020.

28. Veenstra DL, Sullivan SD, Clarke L, et al. Cost effectiveness of Entecavir versus lamivudine with adefovir salvage in HBe-positive chronic hepatitis B. Pharmacoeconomics. 2007; 25: 963-977.

29. Lacey L, Chien RN, Chuang WL, et al. Economic evaluation of chronic hepatitis B treatments in Taiwan. J Gastroenterol Hepatol. 2008; 23: 571-579. 